\title{
On augment-less NPs in Xhosa and de NPs in French
}

\author{
Knut Tarald Taraldsen \\ Department of Language, Culture, The Arctic University of Norway \\ E-mail: knut.taraldsen@uit.no
}

\begin{abstract}
Augment-less NPs in Xhosa and de NPs like de chevaux 'of horses' have strikingly similar properties. It seems that the properties of de NPs reflect the absence of the definite article les which combines with de to form the so-called partitive article des chevaux 'some horses'. Taking the Xhosa augment to be similar (though not identical) to the French definite article, we account for the observed similarities between augment-less NPs and French de NPs.
\end{abstract}

Keywords: Augments; definite articles; situation; semantics; case.

\section{Overview}

This paper is about the augment (also known as the preprefix or the initial vowel), an independent morpheme that is added on top of the basic class prefix of a noun as in $\boldsymbol{a}$-ba-fazi (Aug - Pfx - N) 'women' in Xhosa. The augment (Aug) can fail to appear in certain syntactic environments, but the exact conditions that control its appearance vary across the Bantu languages that have an augment. ${ }^{1}$ In the Xhosa of my consultants , Aug-less NPs are only possible as vocatives, with some modifiers and in apposition to strong pronouns as well as in the scope of negation, e.g. in (1) (see the Appendix for the abbreviations used in the glosses): ${ }^{2}$

$\begin{array}{lll}\text { A-ndi-bon-a-nga } & \text { ba-fazi } & \text { apho } \\ \text { not-I-see-F-not } & \text { 2-woman } & \text { there }\end{array}$

"I didn't see any women there."

I will focus on Aug-less NPs licensed by negation, and concentrate on the Xhosa patterns. The strategy is to identify contrasts between Aug-less NPs and augmented NPs as a way to get at the properties of the augment.

\footnotetext{
${ }^{1}$ De Blois (1970) describes the properties of the augment across a large group of Bantu languages. Buell (2009) provides a summary of some of the literature on the augment in the Nguni languages.

${ }^{2}$ My consultants were 10 students at Stellenbosch University many of whom come from the Eastern Cape. Some of them share the attitude to Aug-drop that Halpert (2016) reports for young Durban speakers of Zulu: They think of using Aug-less NPs (except when used as vocatives or preceded by a demonstrative) as "rude" or characteristic of a slang-like register. They were encouraged to evaluate example sentences as belonging to that register.
} 
Leading up to this, there will be two sections on French. I want to develop a suggestion made in Taraldsen (2010) and argue that the Aug-less NPs in the Xhosa find a very close match in French noun phrases consisting of $d e$ 'of' followed by an article-less NP (henceforth: de NPs): ${ }^{3}$

$\begin{array}{llll}\text { Je n'ai pas } & v u \text { de femmes } & \text { là } \\ \text { I ? ?'have not } & \text { seen of women } & \text { there } \\ \text { "I didn't see any women there." } & \end{array}$

The properties that Aug-less NPs and de NPs have in common are summarized in section 3.4. Since French offers a number of clues that guide the choice of analysis, I will first propose an analysis of the French de NPs and then argue that it carries over to Aug-less NPs in Xhosa. A series of contrasts between the de NPs exemplified in (2) and indefinite noun phrases with de preceding a NP with a definite article, as in (3), will be seen to match contrasts between Augless and (indefinite) augmented NPs in Xhosa suggesting that the Xhosa augment is similar to the French definite article:
J'ai bien $v u$
des femmes
là
I have well seen of-the women
"I certainly saw some women there."

The final outcome will be an analysis that has both a syntactic component and a semantic component that can be seen as a specific implementation of Visser's (2008) proposal that Augless noun phrases are referentially non-specific, while augmented noun phrases are specific (and sometimes also definite).

\section{Background}

In this section, I present some background information on augmented and Aug-less NPs in Xhosa and identify the most important questions that my analysis will address.

\subsection{Augmented NPs}

The augmented forms of nouns in the different noun classes in Xhosa are as shown in (4):

$\begin{array}{clrl}\text { class } 1 & u-m-\mathrm{N} & \text { class } 2 & a-b a-\mathrm{N} \\ 3 & u-m-\mathrm{N} & 4 & i-m i-\mathrm{N} \\ 5 & i-(l i-) \mathrm{N} & 6 & a-m a-\mathrm{N} \\ 7 & i-s i-\mathrm{N} & 8 & i-z i-\mathrm{N} \\ 9 & i-n-\mathrm{N} & 10 & i-z i-/ i i-n-\mathrm{N} \\ 11 & u-(l u-) \mathrm{N} & & \\ 14 & u-(b u-) \mathrm{N} & & \\ 15 & u-k u-\mathrm{N} & & \end{array}$

In all the classes where the basic class prefix contains a vowel, the augment is identical to that vowel. This might suggest that the augment is an underspecified vowel with phonological

\footnotetext{
${ }^{3}$ In agreement with most researchers, I take the negation to be pas rather than $n e$ (omitted in colloquial registers). Accordingly, $n e$ is glossed as? indicating uncertainty with respect to its label.
} 
features added to it from the vowel in the basic prefix by a kind of assimilation, but this line of analysis runs up against difficulties for classes 1 and 3, where the basic prefix has no vowel at the phonological level. It also fails to capture the generalization that the augment is always identical to the vowel in the subject-agreement marker (SC) in the "weak" classes, where the $\mathrm{SC}$ is just a single vowel:

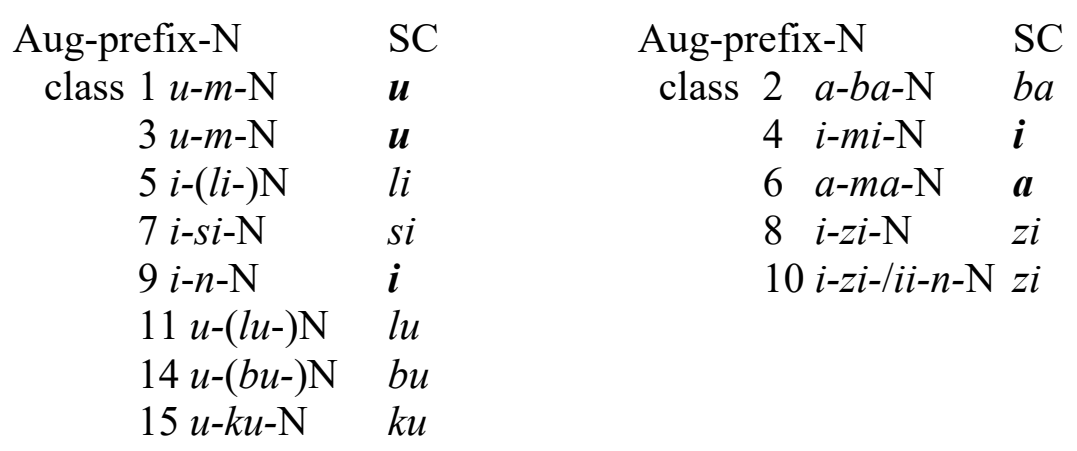

This generalization suggests that the basic prefixes should be parsed as in (6.a) in the "strong" classes, i.e. the ones with a consonant-initial SC, and as in (6.b) in the weak classes:

$$
\begin{array}{lll}
\text { a. } & {[\mathrm{Pfx} C[\mathrm{sc} C[\mathrm{xp} \mathrm{V}]]]} & \text { (strong) } \\
\text { b. } & {[\mathrm{Pfx} m[\mathrm{sc} \text { null }[\mathrm{xP} \mathrm{V}]]]} & \text { (weak) }
\end{array}
$$

The augment would then be a second occurrence of XP:

$$
\text { Aug }-\mathrm{Pfx}=\left[\mathrm{XP} \mathrm{V}_{\mathrm{i}}\right]\left[\mathrm{Pfx} \mathrm{C} / m\left[\mathrm{sc} \mathrm{C} / \text { null }\left[\mathrm{XP} \mathrm{V}_{\mathrm{i}}\right]\right]\right]
$$

Taking the $\mathrm{C} /$ null part of the prefix to correspond to a classifier $\mathrm{N}$ in line with Taraldsen et al (2018), the Aug - Pfx sequence in augmented nouns like $a$-ba-fazi 'the/some women' and $u$ lu-thi 'the/a stick' is comparable to Portuguese a cas- $a$ 'the house' and o carr-o 'the car'.

\subsection{Aug-less NPs}

As for the Aug-less NPs, Mzolo's (1968) observations about tone patterns suggest that Augless NPs come in three varieties. The class prefix of an Aug-less NP has a low tone in one set of syntactic environments, a rising tone in a second set of environments (copulative

\begin{tabular}{|c|c|c|}
\hline $\begin{array}{l}\text { syntax: } \\
\text { vocatives, negation } \\
\text { some modifiers }\end{array}$ & $\begin{array}{l}\text { tone: } \\
\mathrm{pfx}=\mathrm{L}\end{array}$ & $\begin{array}{l}\text { Mzolo's terms: } \\
\text { the vocative form }\end{array}$ \\
\hline copulatives & $\mathrm{pfx}=\mathrm{LH}$ & the copulative form \\
\hline after $k u, k w a, k a$ & $\mathrm{pfx}=\mathrm{L}$ & the simple form \\
\hline
\end{tabular}
constructions) and a high tone in a third set of syntactic contexts:

Since the prefix also has a high tone in augmented NPs, the augment is arguably associated with a high tone that spreads to the prefix, and the low tone on the prefix in the "vocative form" would then follow from the absence of an augment. This would in turn suggest that the Augless NPs with a high tone on the prefix actually have an augment which is null at the segmental 
level, but remains associated with a high tone. The rising tone in the copulative forms could then be the result of this high tone following a low tone introduced by the special copulative formatives.

The Aug-less NPs I will focus on in this article all have a low tone on the prefix, i.e. they have the "vocative form" suggesting that there is not even a segmentally null Aug present in them.

\subsection{Vocatives, appositions and sensitivity to modifiers}

NPs used to address a person, i.e. vocatives, are generally Aug-less. This may be considered similar to the lack of articles in vocatives in European languages. ${ }^{4}$

A NP is also Aug-less when it occurs in apposition to a strong pronoun as in thina lu-sapho lwayo 'us prefix-family yours'. (The augmented form corresponding to lu-sapho is $u$-sapho, since the class 11 prefix $l u$ on polysyllabic nouns drops when preceded by the augment.) As a special case, the NP is Aug-less in superlatives like (8), where it also follows a strong pronoun: ${ }^{5}$

$$
\begin{aligned}
& \text { oyena m-bhali } \quad \begin{array}{l}
\text {-dumile-yo } \\
\text { pro1 1-writer }
\end{array} \text { SC1-be.famous-REL } \\
& \text { "the most famous writer" }
\end{aligned}
$$

When a NP combines with a modifier, the presence of the augment depends on the nature of the modifier. The interrogative - $n i$ 'what kind of' is preceded by an Aug-less NP as in (10), which is used to ask whether you have a boy or a girl: ${ }^{6}$

$$
\begin{array}{ll}
\text { U-na-m-ntwna } & m-n i ? \\
\text { you-with-1-child } & \text { AC1-ni } \\
\text { "What kind of a child do you have?" }
\end{array}
$$

But with the interrogative - $p h i$ 'which', the modified NP seems free to be either augmented or Aug-less: ${ }^{7}$
a.
Ku-fik-e
m-fundi
wu-phi?
SC15-arrive-RP 1-student
SC1-which
"Which student arrived?"
b. Ku-fik-e $\quad \boldsymbol{u}$-m-fundi wu-phi?
SC15-arrive-RP 1-1-student SC1-which
"Which student arrived?"

\footnotetext{
${ }^{4}$ Although articles sometimes may occur, e.g. in the French Salut, les enfants! 'Hello, children' and in the Romanian Domn-ul-e 'Mister!'

${ }^{5}$ The pronoun in this construction has an initial vowel similar to the "relative concord" (RC) discussed in section 7.1. The relative clause is RC-less in (9), but my consultants can also have a RC in the relative clause in the superlative construction.

${ }^{6}$ When -ni modifies a NP, an adjectival concord (AC) agreeing with the NP is prefixed to it, but there is not also an $\mathrm{RC}$ as would be the case when an adjective modifies an augmented NP. Some of my consultants prefer a different way of expressing the meaning of (10): u-no-m-twana o-nja-ni? - you-with.1-1-child RC1-how-ni

${ }^{7}$ A single consultant rejected (11.a). The agreement marker on -phi in the weak classes differs from the regular SCs by having an initial glide $w$ or $y$ just like the "object agreement markers (OCs) (as in Wa-phath-e! - OC6bring-SUBJ - 'Bring them!')
} 
Demonstratives license Aug-less NPs following them, but a NP preceding the demonstrative must be augmented:
a. $\quad *(u-) m-f u n d i \quad l o$
1-1-student Dem1
"this student"
b. lo $(* u-) m-f u n d i$
Dem1 (*1-)1-student
"this student"

This is reminiscent of the fact that a NP preceding a demonstrative has the (suffixed) definite article in Romanian, while a NP following a demonstrative is article-less, e.g. student-ul acesta 'student-the this' vs. acest student 'this student'.

I will not have anything much to say about vocatives, appositions and Aug-less NPs licensed by modifiers except for a few remarks appearing in the footnotes.

\subsection{Sensitivity to clause types and syntactic position}

The main topic of this article is Aug-less NPs that are not vocatives or appositions and do not co-occur with any of the modifiers mentioned in the previous section. An Aug-less NP of this sort was shown in (1):
A-ndi-bon-a-nga
ba-fazi
apho
not-I-see-FV-not 2-woman there
"I didn't see any women there."

My consultants accept such Aug-less NPs in the scope of negation. But unlike negative polarity items (NPIs) like any, Aug-less NPs cannot also appear in questions or if-clauses or other downward entailing environments. Aug-less NPs look like "strict" NPIs. A major challenge for any analysis is to explain why this is so.

It also matters which syntactic position the NP occupies. It is well established that an Aug-less NP cannot be in the preverbal subject position or be dislocated. (13) illustrates this for preverbal subjects:
a.
A-ndi-fun- $i$
not-I-want-NFV
ukuba ku-fik-e
ba-fundi
that SC15-arrive-SUBJ
2-student
"I don't want there to come any students."
b. *A-ndi-fun-I
ukuba ba-fundi
ba-fik-e
not-I-want-NFV that 2-student
"I don't want that any students come."

As (13a) shows, an Aug-less NP can be licensed by negation in a higher close. But it cannot be in a preverbal subject position. 
There are also restrictions on vP-internal Aug-less NPs. While an Aug-less NP immediately following the verb (in a negative sentence) seems acceptable to everyone, the consultants' judgements on Aug-less NPs further away from the verb are less uniform. Halpert (2016) claims that her Zulu consultants accept an Aug-less NP which is not adjacent to the verb, if it is the second object of an applicative or causative verb and attributes this to the way case-licensing works in her analysis. But the judgements of my Xhosa consultants do not replicate Halpert's patterns. Rather, it seems that the most robust generalization is that an Aug-less VP-internal NP cannot follow an augmented VP-internal NP, and I propose an account of this in section 6.

\subsection{Questions to be answered}

I think the basic question to be answered is why Aug-less NPs are only allowed in negative sentences (when they are not vocatives or appositions or co-occur with a modifier). Halpert's (2016) case-based account doesn't seem to offer any answer to this and does not even address the question in any detail.

Carstens and Mletshe (2016), on the other hand, do address the question, but I think their answer is not entirely satisfactory. They claim that Aug-less NPs are "concealed $n$-words", i.e. counterparts of things like French personne 'nobody'/rien 'nothing' and German niemand 'nobody'/nichts 'nothing'. But these don't share the distributional peculiarities of Aug-less NPs in Xhosa (or Zulu). For example, they can appear in the preverbal subject position and they can easily follow a NP that is not also a $n$-word (while an Aug-less NP cannot follow an augmented NP in the Xhosa of my consultants). Moreover, the $n$-words of any given language generally form a small set of items often sharing a specific morpheme, e.g. the $n$ - of niemand and nichts. But the Aug-less NPs in Xhosa and Zulu form an open class just like the class of NPs simply because an Aug-less NP is a syntactic construct, ${ }^{8}$ and there is no special morpheme involved. ${ }^{9}$ Rather, I will claim, it is the absence of a specific morpheme, namely the Aug, that is responsible for the special properties of Aug-less NPs. When not modified by the modifiers mentioned above or used as vocatives or appositions, they behave as strict NPIs just because they are bare NPs.

With this in mind, we now turn to the properties of a type of bare NPs in French.

\section{The properties of indefinite $d e$ NP in French}

In this section, I present the basic facts about the distribution of bare NPs preceded by the preposition de (henceforth: de NPs) in French with a view to highlighting the similarities between de NPs and Aug-less NPs in Xhosa.

\footnotetext{
${ }^{8}$ But Halpert's observation that her Zulu consultants most readily accept Aug-drop with $u$-mu-ntu 'person' and $u$ lu-tho 'thing' might suggest a development of $n$-words parallel to French personne and rien (a descendant of Latin res 'thing').

${ }^{9}$ There might of course be a silent element corresponding the French $n$-word aucun 'no' which co-occurs with a $\mathrm{NP}$ as a determiner/modifier, but like personne 'nobody' and rien 'nothing', aucun NP is also possible as a preverbal subject.
} 


\section{1 de NP vs. des NP in French}

French can form indefinite noun phrases from plurals and mass nouns by adding des to plural NPs and $d u$ or de la to NPs headed by masculine or feminine mass nouns:
a. Je vais acheter des livres
I go buy PA books
"I'm going to buy some books."
b. Elle avait bu du vin
she had drunk PA wine
"She had drunk some wine."

Des (plural), $d u$ (masculine singular) and de la (feminine singular) in indefinite noun phrases like those in (14) are often referred to as "partitive articles" (PA in the glosses in (14)), but look like the regular outcome of having the preposition de precede the definite articles les, le and la as in possessive constructions like (15):
a. l'auteur des livres
the author of.the books
b. le goût $d u$ vin
the taste of.the wine
c. la jupe rouge de la jeune fille
the skirt red of the young girl

Thus, the indefinite des NPs should minimally contain the following structure: ${ }^{10}$

$$
\text { [ de [les/le/la NP ]] }
$$

To account for the fact that the noun following the partitive article cannot be a singular count noun, we may adopt a suggestion by Kayne (2002) positing that the de of the indefinite des NPs introduces silent NUMBER/AMOUNT in its Spec: ${ }^{11}$

\section{[ NUMBER/AMOUNT [ de [ les/le/la NP ]]]}

Thus, an indefinite $d u$ cheval 'of-the horse' is ungrammatical (short of being coerced to 'horse meat') for the same reason as *a number/amount of horse. ${ }^{12}$

Now, the question arises if there are indefinite noun phrases with the structure in (17) except that the NP is bare, i.e. not preceded by a definite article, giving rise to indefinite de NP:

\footnotetext{
${ }^{10}$ The les/le/la NP in (16) does not refer to a contextually salient individual or set of individuals and are in this respect similar to kind-denoting definite NPs in French.

The (suffixed) definite article also occurs in indefinite NPs with plural nouns and mass nouns in Scandinavian varieties.

${ }^{11}$ The term "partitive article" is due to the fact that the set of things picked out by NUMBER/AMOUNT cannot correspond to the totality of things in the denotation of les/le/la NP. In other words, des livres 'PA books' and $d u$ vin 'PA wine' in (14) cannot have the same meaning as les livres 'the books' and le vin 'the wine'.

${ }^{12}$ Possibly [ NUMBER [ $d e$ [ le/la NP]] with a singular count NP and NUMBER $=1$ is blocked by the indefinite article (or numeral) un/une (and similarly for *a number of horse).
} 
In sentences like those in (14), de NP is in fact impossible: ${ }^{13}$

$\begin{array}{cclll}\text { a. } & \text { *Je } & \text { vais } & \text { acheter de } & \text { livres } \\ & \text { I } & \text { go } & \text { buy of } & \text { books } \\ \text { b. } & \text { *Elle } & \text { avait } & \text { bu de din } & \text { vin } \\ & \text { she } & \text { had } & \text { drunk of } & \text { wine }\end{array}$

But in the scope of negation, de NP becomes possible: ${ }^{14}$
a. Je ne vais pas acheter de livres
I ? go not buy of books

"I'm not going to buy any books."

b. Elle n'avait pas bu de vin she ?'had not drunk of wine "She had not drunk any wine."

Thus, it seems that dropping the definite article in (17) creates an NPI - in fact, a strict NPI like the Aug-less NPs in my informants' Xhosa, since sentences like (19) remain ungrammatical even when embedded in downward entailing environments such as if-clauses and questions.

This is the first similarity between the French de NP and Aug-less NPs.

\subsection{The distribution of de NP over syntactic positions}

The distribution of de NP over syntactic positions reveals other similarities between de NP and Aug-less NPs in Xhosa.

Like Aug-less NPs, de NP can also be licensed by negation in a higher clause ${ }^{15}$. The Xhosa sentences in (21) are matched by the French sentences in (22):
a. A-ndi-fun- $i$
ukuba u-sel-e
bu-tywala
not-I-want-NFV
that you-drink
"I don't want that you drink any beer."
b. A-ndi-fun-i
ukuba ku-fik-e
that SC14-come-SUBJ
not-I-want-NFV
"I don't want that any students come."

\footnotetext{
${ }^{13}$ Putting aside the fact that the des of an indefinite des NP may be replaced with de when there is a prenominal adjective in the NP, e.g. Il avait acheté de jolies fleurs - he had bought of pretty flowers - 'He had bought some pretty flowers'.

${ }^{14}$ The noun in a de NP can also be a singular count noun. In this respect, de NPs contrast with indefinite des NPs: Je n'ai pas acheté de cheval vs. *J'ai acheté du cheval. I'll assume that the indefinite article un doesn't block [NUMBER [ (les/le/la) NP ]] with NUMBER $=1$ in the scope of negation.

${ }^{15}$ It is also true that negative concord involving $n$-words can span a clause boundary.
} 


a. Je ne veux pas que tu lises de romans policiers
I "I don't want you to read any mystery books."
b. Je ne veux pas qu'il arrive d'étudiants en retard
I "I don't want students to arrive late."

This is the second similarity between de NP and Aug-less NPs.

The third similarity emerges when we consider which syntactic positions de NP can appear in. It appears in VP-internal positions:
a. Tu ne vas
pas
trouver de livres plus
intéressants
par ailleurs you? go not find of books more interesting "You are not going to find more interesting books elsewhere."
b. Il n' est pas encore arrivé d'étudiants
it ? is not yet arrived of students
"There hasn't arrived any students yet."

But just like Aug-less NPs, it cannot appear in the preverbal subject position, even when the negation is in a higher clause as in (24.b): ${ }^{16}$
a. *D'étudiants ne
sont pas
encore arrivés
of students ?
are not
b.

$\begin{array}{ll}* & \text { ne } \\ \mathrm{I} & ?\end{array}$
veux pas
want
que
yet arrived
d'étudiants
arrivent
arrive
en retard.
of students
late

In this respect, de NPs contrast with indefinite des NPs:
a. Des étudiants sont déjà arrivés
PA students are already arrived
"Some students have already arrived."
b. Elle a confirmé que des étudiants continuent à arriver en retard. she has confirmed that PA students continue to arrive late "She has confirmed that some students continue to arrive late."

Thus, des NPs pattern like augmented NPs in Xhosa.

In addition, there is a restriction that may not be readily comparable with any fact in Xhosa to the extent that it remains to be seen whether Xhosa has prepositions with the same properties as the French prepositions. De NP cannot be inside a PP:

\footnotetext{
${ }^{16}$ Carstens and Mletshe (2016) propose that Aug-less NPs are $n$-words and are licensed under negative concord with negation in a higher clause only if they raise into the clause hosting the negation. They claim that movement of an Aug-less NP from the preverbal subject position of an embedded clause would violate the constraint(s) accountable for the *that-trace effect, and for this reason, the Xhosa counterpart of (24.b) with an Aug-less NP in the position of d'étudiants is ruled out. But, as Halpert (2016) shows for Zulu, an embedded subject can in general raise into the matrix clause crossing the complementizer in Nguni.
} 


$\begin{array}{clllll}* \text { Il } & \text { ne } & \text { veut pas } & \text { jouer avec de filles } \\ \text { he } & ? & \text { wants not play with of girls }\end{array}$

In this respect too, de NPs differ from indefinite des NPs: ${ }^{17}$

$$
\begin{aligned}
& \text { Il veut jouer avec des filles } \\
& \text { he wants play with PA girls } \\
& \text { "He wants to play with some girls." }
\end{aligned}
$$

I offer an account of this fact in section 6.1.

\subsection{Blocking}

The fact that de NP cannot be in the preverbal subject position or inside a PP, as seen in (24) and (26), seems to correlate with another fact. An indefinite des NP is not easily allowed to be in the scope of negation in a sentence like (28): ${ }^{18}$

$$
\begin{array}{clllll}
\text { ?*Elle passe sa } & \text { vie } & \text { en Italie, mais elle ne connaît pas } & \text { des italiens } \\
\text { she spends her } & \text { life in Italy, but she ? knows not AP Italians }
\end{array}
$$

In (28), des NP is in a position where de NP can appear:

$\begin{array}{llllll}\text { Elle passe } & \text { sa vie en Italie, mais elle } & \text { ne } & \text { connaît } & \text { pas } & \text { d'italiens } \\ \text { she spends her life in Italy, but she } ? & \text { knows } & \text { not } & \text { of Italians }\end{array}$

"She is spending a lifetime in Italy, but doesn't know any Italians."

But des NP is fine in the scope of negation in the preverbal subject position and inside PPs:
a. Je ne veux pas que desitaliens viennent te voir I ? want not that PA Italians come you see "I don't want any Italians to come to see you."
b. Elle ne veut pas parler avec des italiens she ? wants not speak with PA Italians "She doesn't want to talk to any Italians."

This suggests that des NP is blocked by de NP in (28). ${ }^{19}$

This recalls a fact about the relative distribution of Aug-less and augmented NPs. According to Halpert (2016), an augmented NP must be interpreted as specific/definite only when it occurs in a position where an Aug-less NP cannot occur.

\footnotetext{
${ }^{17}$ They also differ from $n$-words: Je ne vais parler avec personne 'I'm not going to talk with anyone'.

${ }_{18}$ According to a native speaker, (27) becomes marginally possible if des italiens is contrastively focused. Des italiens, elle n'en connaît pas with topicalized des italiens resumed by en 'of-them' is fine. Sentences with un italien 'an Italian' instead of des italiens pattern like (27) and (29). But un seul italien 'a single Italian' is fine even in a position where $d$ 'italien $(s)$ is also licit: Elle passe sa vie en Italie, mais elle ne connaît pas un seul italien 'She is spending her life in Italy, but she doesn't know a single Italian'. The reasons for this remain to be understood.

${ }^{19}$ If so, this is another respect in which de NP differs from the $n$-words personne'nobody' and rien 'nothing': As shown above, these can occur in the preverbal subject position and inside PPs, but do not block des NP.
} 
This is the fourth similarity between de NP and Aug-less NPs: De NP blocks des NP the same way an Aug-less NPs blocks an augmented NP with an indefinite non-specific interpretation.

\subsection{The similarities between des NP/de NP and augmented/Aug-less NPs}

Taking stock, we have found that de NP (unlike $n$-words) in French matches Aug-less NPs in Xhosa in the following way:

(31) a. Both behave like strict NPIs.

b. Both can be licensed by negation in a higher clause.

c. $\quad$ De NP blocks indefinite non-specific des NP in the scope of negation just like Aug-less NPs block indefinite non-specific augmented NPs in Xhosa.

d. Both are disallowed in the preverbal subject position.

Indefinite des NP, on the other hand, seems comparable to indefinite augmented NPs in Xhosa, suggesting that the augment plays a role similar to the French definite article following de in des NP. ${ }^{20}$

To the extent that the differences between the French indefinite des NP and de NP turn on the presence/absence of the definite article, the similar contrasts between augmented and Aug-less DPs suggest that the Aug is similar to the French definite article and that the Aug-less NPs are just bare NPs like the NP in de NP.

\section{Why the French indefinite de NP and Aug-less nouns in Xhosa look like NPIs}

I will now offer an account for the fact that de NP and Aug-less nouns behave like NPIs. The analysis is first developed for de NP in subsections 4.1-4.3 and an extension to Xhosa is shown in section 4.4 .

\subsection{De NP is not a NPI}

However, de NP is not in itself a NPI. It can also be licensed by connecting to beaucoup and some other quantifier-like elements, e.g. trop 'too many/much' and peu 'few, little', which may precede the main verb just like pas: ${ }^{21}$

$\begin{array}{llllll}\text { Elle } & a & \text { beaucoup } & v u & \text { de films } & \text { italiens } \\ \text { she has } & \text { many } & \text { seen } & \text { of films } & \text { Italian }\end{array}$

"She has seen many Italian films."

In this case too, de NP has to be VP-internal, but cannot be inside a PP:

$$
\begin{aligned}
& \text { a. Il va beacoup venir d'italiens } \\
& \text { it goes many come of Italians } \\
& \text { "There will be many Italians coming." }
\end{aligned}
$$

\footnotetext{
${ }^{20}$ Or more precisely, indefinite des NP and un NP together match the indefinite augmented NPs.

${ }^{21}$ See Obenauer $(1983,1984)$ and references therein.
} 


\begin{tabular}{|c|c|c|c|c|}
\hline b. & $\begin{array}{l}{ }^{*} \text { D'italiens } \\
\text { of Italians }\end{array}$ & $\begin{array}{l}v a \\
\text { goes }\end{array}$ & & $\begin{array}{l}\text { venir } \\
\text { come }\end{array}$ \\
\hline & $\begin{array}{l}\text { veut } \\
\text { wants }\end{array}$ & $\begin{array}{l}\text { beaucoup } \\
\text { many }\end{array}$ & $\begin{array}{l}\text { jouer } \\
\text { play }\end{array}$ & $\begin{array}{l}\text { avec } \\
\text { with }\end{array}$ \\
\hline
\end{tabular}

The similarities between de NP licensed by beaucoup and de NP licensed by pas suggest that pas is a quantifier with the meaning 'not some', that de NP is licensed only when it can connect to a quantifier and that the failure of $d e$ NP to appear as a preverbal subject or inside a PP reflects restrictions on the way the connection between de NP and a preverbal quantifier is established. ${ }^{22}$ The fact that the indefinite des NPs can appear as preverbal subjects and inside PPs then correlates with the fact that des NP need not be licensed by a preverbal quantifier.

The question now is why de NP needs to connect to a preverbal quantifier, but indefinite des NP doesn't. If the quantifiers pas and beaucoup range over individual variables corresponding to NUMBER/AMOUNT in [NUMBER/AMOUNT [ (les) NP]], as in (34), one might say that de NP needs a preverbal quantifier because the $\mathrm{x}$ would not otherwise be bound:

$$
\begin{array}{cc}
*(\text { pas/beaucoup }) \mathrm{V} \ldots[\text { [NUMBER/AMOUNT [ NP ] }] \\
\text { not some } \mathrm{x} / \text { many } \mathrm{x} . . . & \mathrm{x} \ldots
\end{array}
$$

But then, why doesn't the $\mathrm{x}$ in (35) also need to be bound?:

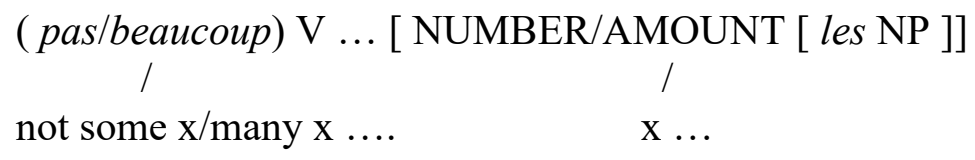

My response to this will be that the individual variable $\mathrm{x}$ can in fact be bound by freely available existential closure both in (34) and in (35). But the bare NP in (34), unlike the les NP in (35), comes with another type of variable which will remain free unless bound by preverbal pas or beaucoup.

\subsection{NP denotations and situations}

A subpart of an extended V-projection can be seen as the description of a set of situations. Simplifying, we could say that a sentence counts as true just in case there actually exists a situation meeting the description delivered by the relevant V-projection. To express this, we can say that this V-projection, for simplicity, the VP, comes with a situation-variable (svariable) bound by an existential quantifier ranging over situations. ${ }^{23}$

The denotation of bare NPs can be taken to be determined with respect to situations. For example, the set of individuals in the denotation of elephant is not necessarily the same in two different situations. So, I will assume that NPs also come with s-variables that must be bound by a quantifier. I'll also take it that the s-variable associated with a NP is distinct from the s-

\footnotetext{
${ }^{22}$ This is not just a matter of c-command, since *Je ne veux pas que d'étudiants viennent en retard is also ungrammatical contrasting with Je ne veux pas que tu lises de romans policiers 'I don't want that you read mystery books'.

${ }^{23}$ Kratzer (2014) and Ramchand (2018) provide recent treatments of situation semantics.
} 
variable of the VP that contains it, but must range over situations that are subparts of any situation assigned as the value of the VP's s-variable. On this view, we will have semantic representations like (36) (suppressing irrelevant details): ${ }^{24}$

$$
\text { some s, } \mathrm{x}\left(\mathrm{VP}(\mathrm{x}, \mathrm{s}) \text { and } \mathrm{NP}\left(\mathrm{x}, \mathrm{s}^{\prime}\right) \text { and } \mathrm{s}^{\prime}<\mathrm{s}\right)
$$

In (36), the VP's s-variable $s$ is bound under existential closure, i.e. free insertion of an existential quantifier binding the VP's s-variable, but the NP's $s$ ' remains free unless another quantifier is added. This is where the need for pas or beaucoup arises. In (37), $s$ ' is bound: ${ }^{25}$

$$
\text { not some s'/many s' some s, } \mathrm{x}\left(\mathrm{VP}(\mathrm{x}, \mathrm{s}) \text { and } \mathrm{NP}\left(\mathrm{x}, \mathrm{s}^{\prime}\right) \text { and } \mathrm{s}^{\prime}<\mathrm{s}\right)
$$

This will account for the dependency of de NP on quantifiers like pas and beaucoup. To account for the fact that indefinite des NPs need not co-occur with such quantifiers, I posit that the definite article inside des NP assigns some specific value to the NP's s-variable, marked as $s_{i}$ in (38.b), which therefore doesn't contain any free situation variables after existential closure has applied:

$$
\begin{aligned}
& \text { a. Elle a vu des films italiens } \\
& \text { she has seen PA films Italian } \\
& \text { "She has seen some Italian films." } \\
& \text { b. } \\
& \text { some } \mathrm{s}, \mathrm{x}\left(\mathrm{VP}(\mathrm{x}, \mathrm{s}) \text { and } \mathrm{NP}\left(\mathrm{x}, \mathrm{s}_{\mathrm{i}}\right) \text { and } \mathrm{s}_{\mathrm{i}}<\mathrm{s}\right)
\end{aligned}
$$

This proposal analyzes indefinite de NP and des NP in a way reminiscent of Halpert's (2016) proposal for Aug-less and augmented NPs. Her idea that Aug-less NPs must be case-marked correspond to my proposal that $d e$ NP has a free situation variable that must be bound from the outside. Her proposal that Aug provides case for an augmented NP is comparable to the idea that the definite article in des NP assigns a value to the NP's situation variable.

I will offer a proposal for the other differences between indefinite des NP and de NP below. But first, we'll look at a fact that seem to support the contention that de NP contains a free situation variable.

\subsection{Some verbs block the connection between pas/beaucoup and de NP}

Beaucoup and pas also occur in the preverbal position in sentences without a de NP:

$$
\begin{aligned}
& \text { a. Elle a beaucoup vu ce film-là } \\
& \text { she has much } \text { "She has seen that film many times." } \\
& \text { b. Elle ne } m \text { 'a même pas adressé } \\
& \text { she la parole } \\
& \text { b me has even not addressed the speech }
\end{aligned}
$$

\footnotetext{
${ }^{24} \mathrm{VP}(\mathrm{x}, \mathrm{s})$ and $\mathrm{NP}(\mathrm{x}, \mathrm{s})$ are intended to mean that the property denoted by VP/NP holds of the individual $\mathrm{x}$ in the situation $\mathrm{s}$, and s' $<\mathrm{s}$ is " $\mathrm{s}$ ' is a part of s". The text analysis is in the spirit of Obenauer $(1983,1984)$.

${ }^{25} \mathrm{~A}$ de NP is also licensed in sentences that contain " $n$-words" like personne 'nobody', rien 'nothing' or jamais 'never', but no (overt) pas. I'll tentatively take it that these too give rise to quantification over situations. For example, Personne ne va acheter de voiture 'Nobody will buy any car' would have the representation 'not some s' some s, x,y (VP(x,y,s) and human $\left(\mathrm{x}, \mathrm{s}^{\prime}\right)$ and $\mathrm{NP}(\mathrm{y}, \mathrm{s}$ ') and s' $<\mathrm{s})$ '.
} 
"She didn't even talk to me."

Here, beaucoup and pas obviously cannot be analyzed as quantifiers ranging over individuals, but they could range over situations:

(40) a. many s (she has seen that film in $\mathrm{s})$

b. not some s (she talked to me in $\mathrm{s}$ )

(40.b) straightforwardly renders the meaning of (39.b), and (40.a) is a plausible reconstruction of the 'often' meaning that beaucoup has in (39.a).

However, with some verbs, e.g. apprécier 'appreciate', beaucoup appears to range over degrees of sentiment rather than situations. Thus, the reading of beaucoup in (41) is 'very much' rather than 'often': 26

$\begin{array}{lllll}\text { Elle a } & \text { beaucoup } & \text { apprécié } & \text { ce film-là } \\ \text { she has much } & \text { appreciated } & \text { that film }\end{array}$

"She appreciated that film very much."

Obenauer $(1983,1984)$ noted that the contrast between (39.a) and (41) with respect to the interpretation of beaucoup seems to be reflected in the contrast between (42.a) and (42.b): ${ }^{27}$
a. Elle a beaucoup vu defilms italiens
she has many seen of films Italian
"She has seen many Italian films."
$\begin{array}{llllll}\text { b. } & \text { Elle a } & \text { beaucoup } & \text { apprécié } & \text { de films } & \text { italiens } \\ \text { she has many } & \text { appreciated } & \text { of films } & \text { Italian }\end{array}$

A contrast of the same type also arises with pas:
$\begin{array}{llllll}\text { a. Elle } & \text { n'a } & \text { pas } & v u & \text { de films } & \text { italiens } \\ \text { she } & \text { ? has } & \text { not } & \text { seen of films } & \text { Italian }\end{array}$
"She hasn't seen any Italian films."

$\begin{array}{llllll}\text { b. } & \text { ?Elle n'a pas apprécié } & \text { defilms } & \text { italiens } \\ \text { she ? has not appreciated of films } & \text { Italian }\end{array}$

This follows if the s-variable $s$ ' associated with the bare NP in (44) needs to be bound by a preverbal beaucoup or pas, since beaucoup/pas can bind s-variables, hence also s', when the verb is voir 'see', but not when the verb is apprécier 'appreciate', judging from (41):

$$
\text { not some/many s'/degrees some s, } \mathrm{x}\left(\mathrm{VP}(\mathrm{x}, \mathrm{s}) \text { and } \mathrm{NP}\left(\mathrm{x}, \mathrm{s}^{\prime}\right) \text { and } \mathrm{s}^{\prime}<\mathrm{s}\right)
$$

The fact that the contrast between (42.a) and (42.b) and between (43.a) and (43.b) is not very sharp (see footnote 27), may be ascribed to coercion facilitated by the presence of the de NP.

\footnotetext{
${ }^{26}$ See Obenauer $(1983,1984)$ and a critique in Doetjes (1994).

${ }^{27}$ The contrast between (42.a) and (42.b) is not black and white. According to two native speakers, it is subtle, but (42.a) is better, and likewise for (43.a) vs. (43.b).
} 


\subsection{Why do Aug-less NPs only occur in the scope of negation?}

I also assume that Aug-less NPs, just like the bare NP in the French de NP, come with a free svariable that must be bound by a quantifier. In French, this quantifier can be either pas or beaucoup. In Xhosa, only a counterpart of pas 'not some' is available. Thus, (45.a) is ungrammatical, but (45.b) is fine: ${ }^{28}$

$$
\begin{aligned}
& \text { a. } \quad \text { Ndi-bon-e ba-fundi } \\
& \text { I-see-RP 2-students } \\
& \text { b. A-ndi-bon-ang-a ba-fundi } \\
& \text { not-I-see-?-FV } \quad \text { 2-student } \\
& \text { "I didn't see any students." }
\end{aligned}
$$

The semantic representations are as in (46):

$$
\begin{aligned}
& \text { a. } \quad \text { some s,x }\left(\operatorname{VP}(x, s) \text { and } N P\left(x, s^{\prime}\right) \text { and } s^{\prime}<\mathrm{s}\right) \\
& \text { b. not some s' some s,x }\left(\operatorname{VP}\left(x, s^{\prime}\right) \text { and } \operatorname{NP}\left(x, s^{\prime}\right) \text { and } s^{\prime}<s\right)
\end{aligned}
$$

In (46.b), the NP's s-variable s' is bound, but in (46.a), it remains free. ${ }^{29}$

As in French, the quantifier corresponding to pas can be in a higher clause:

$$
\begin{aligned}
& \text { A-ku-funek-i } \quad \text { si-pheke n-yama } \\
& \text { not-SC15-is.necessary-NFV we-cook-SUBJ 9-meat } \\
& \text { "It isn't necessary that we cook any meat." }
\end{aligned}
$$

Like the French definite article le, la, les both in indefinite des NPs and in definite noun phrases, the Aug will be taken to assign a specific value to the NP's s-variable. Therefore, augmented nouns do not need to be in the scope of a clause-level operator binding the NP's s-variable.

\subsection{Varieties of Xhosa where Aug-less NPs are not strict NPIs}

Visser (2008) and von Staden (1973) describe a variety of Xhosa that differs from the Xhosa spoken by my consultants by allowing Aug-less NPs not only in the scope of negation, but also in questions:

\footnotetext{
${ }^{28}$ For convenience, I take it that the element corresponding to pas in (45.b) is the initial $a$, but the relationship between this $a$ and other exponents of negation, e.g. the -ang, remains to be worked out. (Possibly, the correct parse of (45.b) is bon-a-nga with nga as an "auxiliary verb" following a main verb with its usual final vowel.)

${ }^{29}$ Given the deictic nature of demonstratives, it seems plausible that a demonstrative too can provide a value for the s-variable of an Aug-less NP, but it remains to be seen why this cannot happen when the demonstrative follows the NP. In vocatives, the s-variable of the Aug-less NP may be assigned the discourse situation as its value. Marianna Visser (pc.) brought the following example to my attention:

$\begin{array}{llll}\text { (i) } U \text {-m-fazi } & \text { u-biz-e } & \text { n-tombi } & \text { e-thile } \\ \text { 1-1-woman } & \text { SC1-call-RP } & \text { 9-girl RC } & \text { 9-certain } \\ \text { "The woman called a certain girl." } & \end{array}$

Here too, the Aug-less NP is not in the scope of negation.It may be that thile 'certain' has a way of assigning a specific value to the s-variable of the NP it modifies.
} 


$$
\begin{aligned}
& \text { U-bon-e } \quad \text { n-dlovu na? } \\
& \text { you-see-RP } \\
& \text { "Did you see any elephant } Q
\end{aligned}
$$

The analysis set out above provides a straightforward characterization of this kind of Xhosa (henceforth: Archaic Xhosa, for want of a better term). We may take the s-variable associated with the Aug-less NP to be bound by a question operator Q assigning (48) a representation like (49):

$$
\text { Q s' some } \mathrm{s}, \mathrm{x}\left(\mathrm{VP}(\mathrm{x}, \mathrm{s}) \text { and } \mathrm{NP}\left(\mathrm{x}, \mathrm{s}^{\prime}\right) \text { and } \mathrm{s}^{\prime}<\mathrm{s}\right)
$$

In a semantic analysis of interrogatives based on Hamblin (1973), a question is represented as the set of declarative sentences that count as possible answers to it, e.g. the question in (48) would map onto a set whose members include the statements in (50), where Harry and Sally are the names of particular elephants:

$$
\text { \{ I saw Harry, I saw Sally, ... }\}
$$

The statements in this set can be seen as descriptions of the situations that would make the proposition 'I saw an elephant' true. The interrogative operator Q is then the element that triggers the construction of a set of alternatives like (50).

Doke (1927) claims that Aug-less NPs in Zulu typically appear in questions he defines as "axiomatic". The questions in (51), for example, are axiomatic in the sense that they, as the translations suggest, are not about particular individuals: ${ }^{30}$

$$
\begin{array}{llll}
\text { a. } & \text { U-bon-a } & \text { mu-ntu nje na? } \\
\text { you-see-FV 1-person at all Q } \\
\text { "Do you see anybody at all? or any person?" } \\
\text { b. } \quad \text { Ku-khona ba-ntu nje lapha? } \\
\text { SC15-present 2-person at all here } \\
\text { "Are there any people here at all?" }
\end{array}
$$

Consider now the question in (52.a) with an augmented object NP:

$$
\begin{array}{lll}
\text { a. } & \text { U-bon-e } & \text { i-n-dlovu? } \\
& \text { you-see-RP } & \text { 9-9-elephant } \\
\text { b. } & \mathrm{Q} \mathrm{s}, \mathrm{x}\left(\mathrm{VP}(\mathrm{x}, \mathrm{s}) \text { and } \operatorname{NP}\left(\mathrm{x}, \mathrm{s}_{\mathrm{i}}\right) \text { and } \mathrm{s}_{\mathrm{i}}<\mathrm{s}\right)
\end{array}
$$

On the analysis developed above, $s_{i}$ is assigned a specific situation as its value by the augment. As a consequence of this, the set of possible answers to (5.a) will be a proper subset of the set of possible answers associated with (48). For example, there may be no individual called Harry among the elephants in $\mathrm{si}$, although there may be one in some other s'. Thus, a sentence formed by conjoining all the members of the set of possible answers to (48) will entail a statement

\footnotetext{
${ }^{30}$ The examples are from Doke (1927), who says that axiomatic statements with Aug-less NPs mostly contain negation, and otherwise are generally interrogative and often incorporate nje 'at all'.
} 
corresponding to the conjunction of the members of the set associated with (52.a). In this sense, (48) may be said to be stronger, or more "axiomatic", than (52).

Doke's intuition about Aug-less NPs is similar to Dayal's (1998: 467) statement that an English sentence like Did you see any elephants? is not about a contextually relevant set of elephants, but about any possible elephant. In her analysis of the NPI any, as in my analysis of the French de NP and the Aug-less NPs in Xhosa, this intuition is captured by having the s-variable of a NP (the NP modified by any) bound by an existential quantifier. Whereas the question in (52.a) can only be about the individuals that are elephants in the particular situation $\mathrm{si}_{\mathrm{i}},(48)$ is about all individuals that happen to be elephants in some situation or other. ${ }^{31}$

Dayal also adds that the intuition just reported corresponds to "the well-known intuition about an any statement being stronger than a statement with the regular quantifier", and we have just seen how this plays out in the case of (48) vs. (52.a).

The question why Aug-less NPs are not allowed in interrogatives in the Xhosa spoken by my consultants, is difficult to answer in an interesting way. The best suggestion available at this juncture is that the interrogative operator Q has lost its ability to bind an s-variable associated with a NP in yes/no-questions. In other questions, $(u-) b a-n i$ 'who' and (i-) $n$-to-ni 'what' still occur regularly without the augment, although the augmented forms are also possible. ${ }^{32}$

\section{Blocking}

In section 3.3., we noticed that an indefinite des NP seems to blocked by the availability of a de NP in the same position, and that a non-specific reading is blocked for an augmented NP, if an Aug-less NP could be used instead. Now, I will consider the possibility of accounting for both blocking effect within the unified analysis of French and Xhosa developed above.

\section{$5.1 \quad$ de NP blocking des NP}

I have pointed out that paradigms like (53) suggest that de NP somehow blocks des NP in negative sentences:

\begin{tabular}{|c|c|c|c|c|c|}
\hline a. & $\begin{array}{l}\text { Elle } \\
\text { she }\end{array}$ & $\begin{array}{l}\text { ne } \\
?\end{array}$ & $\begin{array}{l}\text { connaît } \\
\text { knows }\end{array}$ & $\begin{array}{l}\text { pas } \\
\text { not }\end{array}$ & $\begin{array}{l}\text { d'italiens } \\
\text { of Italians }\end{array}$ \\
\hline & \multicolumn{5}{|c|}{ "She doesn't know any Italians." } \\
\hline b. & $\begin{array}{c}?^{*} \text { Elle } \\
\text { she }\end{array}$ & $\begin{array}{l}n e \\
?\end{array}$ & $\begin{array}{l}\text { connaît } \\
\text { knows }\end{array}$ & $\begin{array}{l}\text { pas } \\
\text { not }\end{array}$ & $\begin{array}{l}\text { des italiens } \\
\text { PA Italians }\end{array}$ \\
\hline c. & $\begin{array}{c}* \text { Elle } \\
\text { she }\end{array}$ & $\begin{array}{l}\text { ne } \\
?\end{array}$ & $\begin{array}{cc}\text { parle pas } \\
\text { talks not }\end{array}$ & $\begin{array}{l}\text { avec } \\
\text { with }\end{array}$ & $\begin{array}{l}\text { d'italiens } \\
\text { of Italians }\end{array}$ \\
\hline d. & $\begin{array}{l}\text { Elle } \\
\text { she }\end{array}$ & $\begin{array}{l}\text { ne } \\
?\end{array}$ & $\begin{array}{cc}\text { parle pas } \\
\text { talks } & \text { not }\end{array}$ & $\begin{array}{l}\text { avec } \\
\text { with }\end{array}$ & $\begin{array}{l}\text { des italiens } \\
\text { PA Italians }\end{array}$ \\
\hline
\end{tabular}

\footnotetext{
${ }^{31}$ This makes Aug-less NPs look similar to NPs in generic sentences, and this might help one understand why the interrogative - $n i$ ' what kind' combines with Aug-less NPs.

32 The fact that the augment is possible here, suggests that the $-n i$ is not quite the same as the -ni in (*a-) ba-ntwana $b a-n i$ 'what kind of children' (see section 2.3.).
} 


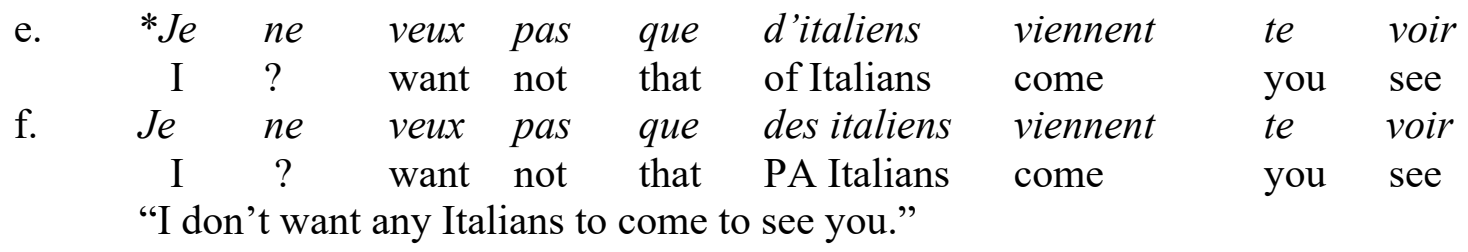

We have also seen a similar effect in Xhosa. As Halpert (2016: 88) notes for Zulu, an augmented NP in the scope of negation is necessarily interpreted as specific/definite if it is in a position where Aug-less NPs are possible. In (54.b), the augmented NP amaNgesi must be specific/definite, but not in (54.d):
a. A-ndi-fun-i
ukuba ku-fike
ma-Ngesi
not-I-want-NFV
that SC15-come-SUBJ
6-Englishman
"I don't want there to come any Englishmen."

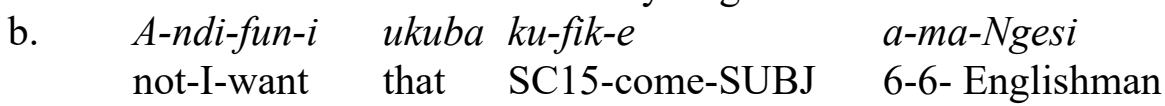
"I don't want the/some Englishmen to come."
$\begin{array}{ll} & * A-n d i-f u n-i \\ & \text { not-I-want-NFV }\end{array}$
ukuba ma-Ngesi a-fik-e
d. A-ndi-fun-i
that 6-Englishman SC6-come-SUBJ
not-I-want-NFV
ukuba a-ma-Ngesi
a-fik-e
"I don't want any Englishmen to come."

The claims made in sections 4.2-4.4 suggest an account of this blocking effect. Both (53.a), with a de NP, and (54.a), with an Aug-less NP, have a semantic representation like (55) with $s$ ' a situation variable bound by some s':

$$
\text { not some s' some s, } \mathrm{x}\left(\mathrm{VP}(\mathrm{x}, \mathrm{s}) \text { and } \mathrm{NP}\left(\mathrm{x}, \mathrm{s}^{\prime}\right)\right. \text { and s' < s) }
$$

On the assumption that the definite article in French des NPs and the Aug in augmented NPs in Xhosa assign a value to the NP's situation variable, the semantic representation of (53.b) and (54.b) is (46), where $s_{i}$ is assigned some specific situation as its value by the les inside des italiens and by the Aug in $a-m a-N g e s i:{ }^{33}$

$$
\text { not some } \mathrm{s}, \mathrm{x}\left(\mathrm{VP}(\mathrm{x}, \mathrm{s}) \text { and } \mathrm{NP}\left(\mathrm{x}, \mathrm{s}_{\mathrm{i}}\right) \text { and } \mathrm{s}_{\mathrm{i}}<\mathrm{s}\right)
$$

(55) entails (56), but (56) does not entail (55). Therefore, (53.a) and (54.a) are stronger statements than (53.b) and (54.b). For this reason, I suggest, (53.a) blocks (53.b), and (54.a) blocks (54.b) with an any reading. This is in line with Kadmon and Landman's (1993) proposal that any is only licensed if it produces a statement stronger than a similar sentence with some. ${ }^{34}$

I assume that only indefinite noun phrases compete with de NP and Aug-less NPs. Therefore, (57) is not blocked by (53.a), and (54.a) does not block (54.b) with a definite reading of $a$-maNgesi:

\footnotetext{
${ }^{33}$ In (46), pas binds the s associated the VP rather than a part s' of s, and existential closure doesn't apply.

${ }^{34}$ As in Kadmon and Landman's account, the reason a de NP yields a stronger statement than a des NP, is that de NP allows a widening of the NP's denotation. Here, this corresponds to its being evaluated with respect to more than a single situation.
} 


$\begin{array}{lllll}\text { Elle } & \text { ne } & \text { connaît } & \text { pas } & \text { les italiens } \\ \text { she } & \text { knows } & \text { not } & \text { the Italians }\end{array}$

"She doesn't know the Italians."

A des NP, unlike an augmented NP in Xhosa, can never be interpreted as definite, and therefore, (53.b) cannot be unblocked by assignment of a definite reading of des italiens. However, it is surprising that it cannot be assigned an indefinite specific reading like $a$-ma-Ngesi. The question why this is, will left open here. ${ }^{35}$

The fact that (53.d) and (53.f) are fine and apparently allow an any interpretation, correlates with the fact that (53.c) and (53.e) are ungrammatical so that there are no stronger statements blocking (53.d) and (53.f), and similarly for (54.d).

\subsection{A note of the any reading of des NP and augmented NPs}

It should be clear that I take the des NP in (53.d) and (53.f) and the augmented NP in (54.d) to give rise to the same semantic representation as in the blocked (53.b) and (54.b). In particular, the s-variable of the NP is assigned a specific value whereas the s-variable of a de NP and an Aug-less NP is bound by a clause-level existential quantifier. This means that the any reading cannot correspond directly to the NP's s-variable being bound by an existential quantifier.

The any reading of des italiens in (53.d) and (53.f) suggested by the translations as well as the any reading of a-ma-Ngesi in (54.d) may arise because des italiens 'PA Italians' and a-maNgesi are non-specific in the sense that they involve existential quantification over the individuals that are in the denotation of italiens 'Italians' and ma-Ngesi 'Englishmen' in $\mathrm{s}_{\mathrm{i}}$ rather than reference to a specific individual. It may also be an artefact of translation, since there are no stronger statements with d'italiens competing with (53.d) and (53.f), and She doesn't talk with any Italians and I don't want any Italians to come to see you are the strongest corresponding statements in English, and likewise for (54.d).

35 But some of my consultants strongly prefer (i.a), with dislocated $a$-ba-ntwana doubled by an OC, over (i.b) when $a$-ba-ntwana is interpreted as indefinite:

(i) $\quad$ a. $\quad A$-ndi-b-azi a-ba-ntwana

not-I-OC2-know 2-2-child

"Children, I don't know any of."

b. A-nd-azi a-ba-ntwana

not-I-know 2-2-child

"I don't know any children."

(i.a) seems parallel to the French (ii), with topicalized des italiens, which is perfectly acceptable to speakers who find (53.b) degraded:

(ii) Des italiens, elle n'en connaît pas

PA Italians she ? of.them knows not

"Italians, she doesn't know any of."

In (i.a), the object concord $b a$ looks like Xhosa counterpart of $e n$ in the French (ii). 


\section{The distribution over syntactic positions}

We have noted that both de NP and Aug-less NPs are disallowed in the preverbal subject position. In this section, I offer a specific proposal why this is so. I also present an account of restrictions on Aug-less NPs that have no observable counterpart in French.

\subsection{Why do certain syntactic positions disallow de NP?}

We have already seen that de NP linked to preverbal beaucoup or pas cannot be in the preverbal subject position or inside a PP. Following Kayne (2002), I now suggest that this reflects restrictions on case-driven movement of the bare NP to a VP-external position leading to an analysis closer to Halpert's (2016) case-based account of the augmented and Aug-less noun phrases in Zulu. ${ }^{36}$

The basic idea is that both NUMBER/AMOUNT and the NP in [ NUMBER/AMOUNT [(les) NP ]] are both nominal elements that need case-marking and don't get case-marked by caseassignment to the whole phrase. Rather, the head assigning case to a direct object only assigns case to NUMBER/AMOUNT, while the NP has to be case-marked in some other way. The proposal is then that there is a VP-external head K-de assigning case to the NP of [ NUMBER/AMOUNT [ NP ]] provided this NP raises to Spec-K-de:

$$
\text { [ NP [ K-de [vp ... [ NUMBER/AMOUNT NP ] ]]] }
$$

But K-de must be licensed by $d e$ merging immediately above $\mathrm{K}-d e \mathrm{P}$, and de attracts the remnant VP to its Specifier:

$$
[[\mathrm{vP} \ldots[\text { [ NUMBER/AMOUNT NP }]][\text { de [ NP [ K-de VP ]]]] }
$$

The fact that de NP cannot be inside a PP then follows from whatever blocks extraction from PPs in French, which doesn't allow P-stranding. ${ }^{37}$ The fact that de NP cannot be a preverbal subject is also a consequence of remnant VP movement across de. As with other instances of de NP, the NP embedded under NUMBER/AMOUNT in a subject $d e$ NP must raise to Spec$\mathrm{K}-d e$ to be case-licensed, but subsequently, the remnant VP must raise to Spec-de, and therefore, a subject de NP cannot be preverbal.

This case-based account of de NP presupposes that the NP inside indefinite des NP and beaucoup des NP need not raise to the VP-external K-de to be assigned case, since indefinite des NP can appear inside PPs and in the preverbal subject position. This suggests that the definite article following de in des NP makes a local K-de available. With indefinite des NP, we then have the following derivation:

$$
\begin{aligned}
& \text { [ K-de [NP NUMBER/ AMOUNT [ les NP ]]] } \\
& \rightarrow[[\text { les NP] [K-de [NP NUMBER/AMOUNT tes NP ]]] } \\
& \rightarrow[\text { de [[ les NP] [ K-de [NP NUMBER/AMOUNT tes NP ]]]] } \\
& \rightarrow[[\mathrm{NP} \text { NUMBER/AMOUNT tes NP }][\text { de [[ les NP ] [K-de NP ]]]] }
\end{aligned}
$$

\footnotetext{
${ }^{36}$ An alternative line of analysis in the spirit of Collins and Postal (2014) would take pas and preverbal beaucoup to move out of the Specifier position in [ pas/beaucoup [ de NP ]].

${ }^{37}$ Kayne $(1981,1983)$ presents an account of this fact that extends to subextraction from the complement of a P.
} 
In conjunction with the proposals in section 4.2, this means that two apparently distinct properties are now attributed to the definite article. It assigns a value to the NP's s-variable, and it makes a local case-licensing head available (as does the Aug in Halpert's (2016) analysis). Whether these two properties can be unified will have to remain an open question for now.

This account of the restrictions on French de NPs extends to Xhosa Aug-less NPs provided that Aug-less NPs form a constituent with an element like NUMBER/AMOUNT at the initial step of the derivation just like French $d e$ NPs. Then, the derivation proceeds as in French except that the Xhosa counterpart of the French de merged above K-de must be silent:

$$
\begin{aligned}
& {[\text { NP }[\text { K-of }[\mathrm{vP} \ldots[\text { [ NUMBER/AMOUNT NP }]]]] \rightarrow} \\
& {[[\mathrm{vP} \ldots[\text {... NUMBER/AMOUNT NP }]][\text { OF }[\mathrm{NP}[\mathrm{K} \text {-of VP }]]]]}
\end{aligned}
$$

In Halpert's (2016) analysis, Aug-less NPs must be case-marked by a vP-external head L probing into $\mathrm{vP}$, while the case of augmented NPs is provided by Aug. This L corresponds to the VP-external K-de in my analysis of French in, but unlike what Halpert assumes for L, K-de will require the NP it case-marks to be its Specifier.

As for augmented NPs, we may assume the same analysis as for the French indefinite des NPs with a local K-of licensed by the Aug the same way local K-de is licensed by les, the definite article, in French indefinite des NP: ${ }^{38}$

\section{[[NP NUMBER/AMOUNT Aug NP ] [OF [[ Aug NP ] [K-of NP ]]]]}

In this case, the Aug provides case-licensing as in Halpert's analysis, but indirectly, by licensing a local K-of. ${ }^{39}$

\subsection{Syntactic restrictions on Aug-less NPs not shared with de NP}

In addition to the ban on Aug-less NPs in the preverbal subject position, there are certain other restrictions that we now turn to. When presented with the examples in (63), 5 out of 9 consultants accepted them all except for (63.d) and 2 accepted only (63.b-c): ${ }^{40}$
a.
U-m-limi
a-ka-bon-is-ang-a
ba-ntwana
$i-z i-n-j a$
1-1-farmer
not-SC1-see-CAU-?-FV 2-child
10-10-10-dog
"The farmer didn't show any children the dogs."
b. U-m-limi a-ka-bon-is-ang-a ba-ntwana zi-n-ja
1-1-farmer not-SC1-see-CAU-?-FV 2-child 10-10-dog
"The farmer didn't show any children any dogs."

\footnotetext{
${ }^{38}$ The fact that an indefinite augmented NP can have a singular count noun whereas the noun must be either a plural or a mass noun in the French indefinite des NPs, will be taken to follow from Xhosa having no indefinite article like French $u n$ blocking [ NUMBER NP] with NUMBER $=1$.

${ }^{39}$ If a demonstrative also licenses a local K-of, an Aug-less NP preceded by a demonstrative may have the structure

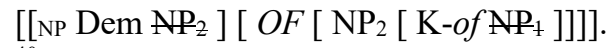

${ }^{40}$ Halpert (2016) reports that her Zulu consultants accept sentences like (68.d), and her analysis is designed to allow for all the patterns in (68).
} 


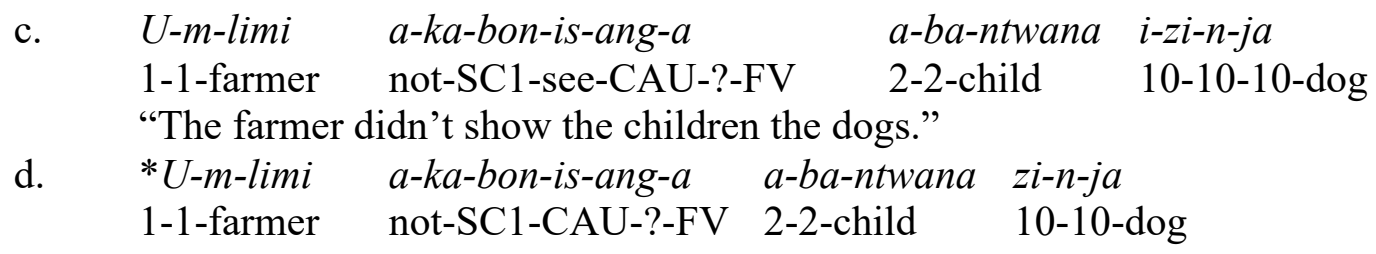

One consultant only accepted (63.c), but this particular speaker consistently rejects Aug-less NPs in any context (except when used as vocatives or following a demonstrative). Another consultant accepted all the examples in (63) including (63.d) replicating Halpert's Zulu pattern.

Thus, the majority of the consultants reject double object constructions where an augmented NP is followed by an Aug-less NP. In addition, 2 speakers within the majority group also reject an augmented NP following an Aug-less NP. ${ }^{41}$ The patterns accepted by the majority of my consultants are shown in (64), where + represents an augmented NP and - an Aug-less NP:
a. $\quad(*) \mathrm{V}-+$
b. $\quad \mathrm{V}-\mathrm{-}$
c. $\mathrm{V}++$
d. $\quad * \mathrm{~V}+-$

In (64.a), $(*)$ indicates that this pattern is unacceptable to a subset of the majority speakers.

In the next subsection, I sketch an analysis which is primarily designed to rule out the pattern (64.d), but can also accommodate the speakers that also find (64.a) unacceptable.

\subsection{Evacuation movement}

As a starting point, I first address the question how the right word order emerges on the analysis of Aug-less NPs proposed in subsection 6.1. According to that analysis, the Aug-less ba-ntwana 'any children' in (65) must be the Specifier of a VP-external K-of, and the remnant VP has moved across it:

$\begin{array}{lcl}\text { A-ndi-thum-el-ang-a } & \text { ba-ntwana } & \text { i-mali } \\ \text { not-I-send-APPL-?-FV } & \text { 2-child } & \text { 9-money } \\ \text { "I didn't send any children money." } & \end{array}$

But if the second object, $i$-mali 'the money' is VP-internal, the outcome of the derivation should have been the ungrammatical (66.a):
*A-ndi-thum-el-ang-a
i-mali
ba-ntwana not-I-send-APPL-?-FV
9-money
2-child
b. [[vp a-ndi-thum-el-ang-a ba-ntwana i-mali $][$ OF [ ba-ntwana [K-of VP ]]]]

The generalization is that movement to the VP-external K-of doesn't affect the word order dictated by the theta-properties of the different argument NPs. To capture this, I now propose

\footnotetext{
${ }^{41}$ With some other verbs, e.g. with $a$-ka-thum-el-ang- $a$ 'he didn't send', the number of speakers accepting only double object constructions where both NP are augmented or both are Aug-less, was higher.
} 
that the derivation includes obligatory evacuation movement of augmented NPs from the VP applying before VP-external K-of is merged: ${ }^{42}$
[vP V NP Aug-NP ] $\rightarrow$ (evacuation movement)
[eP Aug-NP [vp V NP Aug-NP ]] $\rightarrow$ (merger of K-of)
[ K-of [EP Aug-NP [vP V NP Aug-NP ]]] $\rightarrow$ (the Aug-less NP moves to Spec-K-of)
[ NP [ K-of [ep Aug-NP [vp V NP Aug-NP ]]]] $\rightarrow$ (merger of $O F$ and VP-movement)
[[vp V NP Aug-NP ] [ OF [ NP [ K-of [ep Aug-NP VP ]]]]]

Given the determiner-like properties of Aug, this is reminiscent of Diesing (1992).

I also assume that an evacuated NP cannot subsequently raise to K-of, and that evacuation movement only applies to $\mathrm{V}$-projections so that if $\alpha, \beta$ and $\gamma$ are $\mathrm{V}$-projections in (68), each of these can be evacuated, but nothing else: ${ }^{43}$

$$
\left[\mathrm{vP} \mathrm{V}\left[\alpha \mathrm{NP}_{1}\left[\beta \mathrm{NP}_{2}\left[{ }_{\gamma} \mathrm{NP}_{3}\right]\right]\right]\right]
$$

Thus, omitting traces, the possible outcomes of evacuation movement are:

$$
\begin{aligned}
& \text { a. } \quad\left[\operatorname{EP}[\gamma \text { Aug-NP } 3]\left[\mathrm{vP} \mathrm{V}\left[\alpha(* \text { Aug- }) \mathrm{NP}_{1}\left[{ }_{\beta}(* \text { Aug- }) \mathrm{NP}_{2}\right]\right]\right]\right] \\
& \text { b. } \quad\left[\mathrm{eP}\left[\beta \text { Aug-NP } 2\left[\gamma(\text { Aug- }) \mathrm{NP}_{3}\right]\right]\left[\mathrm{vP} \mathrm{V}\left[\alpha(* \text { Aug- }) \mathrm{NP}_{1}\right]\right]\right] \\
& \text { c. } \quad\left[\text { EP }\left[\alpha \text { Aug-NP } 1\left[\beta *(\text { Aug- }) \mathrm{NP}_{2}\left[\gamma *(\text { Aug- }) \mathrm{NP}_{3}\right]\right]\right][\mathrm{vP} \mathrm{V}]\right]
\end{aligned}
$$

$\mathrm{NP}_{1}$ and $\mathrm{NP}_{2}$ cannot be augmented in (69.a) and $\mathrm{NP}_{1}$ cannot be augmented in (69.b), since if they were augmented, the minimal V-projection containing them would be evacuated. Conversely, $\mathrm{NP}_{3}$ must be augmented in (69.b) and $\mathrm{NP}_{2}$ and $\mathrm{NP}_{3}$ must be augmented in (69.c) given the assumption that a case-less NP cannot raise to Spec-K-of after it has been evacuated.

The Aug-less $\mathrm{NP}_{1}$ and $\mathrm{NP}_{2}$ in (69.a) and the Aug-less $\mathrm{NP}_{1}$ in (69.b) then raise to Spec-K-of:44

$$
\begin{aligned}
& \text { a. } \quad\left[\mathrm{KP} \mathrm{NP}_{1}\left[\mathrm{NP}_{2}\left[\mathrm{~K} \text {-of }\left[\mathrm{EP}\left[\gamma \text { Aug- } \mathrm{NP}_{3}\right][\mathrm{vP} \mathrm{V}]\right]\right]\right]\right] \\
& \text { b. } \quad\left[\mathrm{KP} \mathrm{NP}_{1}[\mathrm{~K}-o f[\mathrm{eP}[\beta \text { Aug-NP } 2[\gamma \text { Aug-NP } 3][\mathrm{vP} \mathrm{V}]]]]\right.
\end{aligned}
$$

Movement of the remnant VP then restores the underlying word order: ${ }^{45}$

$$
\begin{array}{ll}
\text { a. } & {[o F \mathrm{P}[\mathrm{VP} \mathrm{V}]]\left[O F \left[\mathrm { KP } \mathrm { NP } _ { 1 } \left[\mathrm{NP}_{2}[\mathrm{~K}-o f[\mathrm{EP}[\gamma \text { Aug-NP }\right.\right.\right.} \\
\text { b. } & {\left[o F \mathrm{P}[\mathrm{VP} \mathrm{V}]\left[O F\left[\mathrm{KP} \mathrm{NP}_{1}\left[\mathrm{~K}-o f\left[\mathrm{EP}\left[\beta \text { Aug-NP } 2\left[\gamma \text { Aug-NP } \mathrm{NP}_{3}\right]\right]\right]\right]\right]\right]\right.}
\end{array}
$$

\footnotetext{
${ }^{42}$ For convenience, the higher projection into which augmented NPs are evacuated is labelled EP in (82).

43 The second of these two assumptions is modelled on Nilsen's (2003) account of fact that the second object cannot be shifted across the first object in a double object construction in Scandinavian even when it is a weak pronoun.

${ }^{44}$ To accommodate multiple raising to Spec-K-of, we may have to allow multiple Specs. The projection holding the occurrences of Spec-K-of is labelled KP.

${ }^{45}$ Remnant VP-movement must also apply to (74.c), i.e. $O F$ cannot be the (only) trigger for VP-fronting.

Traces are omitted in (85)-(86) and the projection holding the occurrences of Spec-K-of is labelled KP.
} 
Movement of the remnant VP in (69.c) produces a structure where the verb is followed by three augmented NPs, whereas it will be followed by three Aug-less NPs, if nothing has been evacuated.

Thus, the assumption that the smallest V-projection containing an augmented NP must be evacuated guarantees that an Aug-less NP cannot follow an augmented NP, i.e. the V + - pattern in (64.d) cannot be generated, and the judgement on (64.d) by the majority of my consultants is accounted for.

As noted, some speakers only accept the patterns $\mathrm{V}++$ and $\mathrm{V}--$, where either both NPs are Aug-less or both are augmented. This is consistent with my analysis, but an extra assumption is needed to exclude the pattern $\mathrm{V}-+$, which will be generated if the lowest V-projection can freely be evacuated out of a higher one. For the relevant speakers, this must be impossible, i.e. evacuation movement of $\beta$ in (72) must pied-pipe $\alpha$ :

$$
\left.\left[\mathrm{EP}\left[\alpha \mathrm{NP}_{1}[\beta \text { Aug-NP} 2]\right]\right][\mathrm{VP} \mathrm{V}]\right]
$$

\subsection{Aug-less NPs in the possessive construction}

This line of analysis should extend to possessive constructions. These are formed by placing the possessee in the Spec-position of the "linker" $a$ 'of' followed by the NP denoting the possessor, and a SC agreeing with the possessee is prefixed to the linker:

$$
\begin{aligned}
& \text { a-ba-ntwana } \text { b-o-m-limi } \\
& \text { 2-2-child } \\
& \text { "the farmer's children" }
\end{aligned}
$$

In (73), the possessor NP is augmented: The - $o$ - is the outcome of coalescing the augment $u$ - of $u$-m-limi 'the/a farmer' with the linker $a:^{46}$

\section{a-ba-ntwana b-a u-m-limi $\rightarrow$ a-ba-ntwana b-o-m-limi}

But in the scope of negation, the possessor NP may be Aug-less provided that the possessee is also Aug-less:
a. A-nd-azi ba-ntwana b-a-m-limi
not-I-know 2-child SC2-of-1-f
"I don't know any children of any farmer."
b. *A-nd-azi a-ba-ntwana b-a-m-limi
not-I-know 2-2-child SC2-of-1-farmer

The excluded + - pattern seems parallel to the contrast in (76) and is accounted for if evacuation movement must apply to the smallest N-projection that contains an augmented NP ( $\alpha$ in (77)) rather than to the augmented NP itself: ${ }^{47}$

\footnotetext{
${ }^{46}$ Coalescence produces $o$ from $a u$ and $e$ from $a i$.

${ }^{47}$ Halpert (2016) accounts for the contrast exemplified by (75.a) vs. (75.b) by saying that a possessor NP can be Aug-less only under case-agreement with the possessee, which then must also be Aug-less ( = case-marked).
} 


$\begin{array}{lllll}\text { a. } & \text { U-m-limi } & \text { a-ka-bon-is-ang- } a & \text { ba-ntwana } & \text { zi-n-ja } \\ \text { 1-1-farmer } & \text { not-SC1-see-CAU-?-FV } & \text { 2-child } & 10-10-\mathrm{dog} \\ & \text { "The farmer didn't show any children any dogs." } \\ \text { b. } & \text { *U-m-limi } & a-k a-b o n-i s-a n g-a & a-b a-n t w a n a & \text { zi-n-ja } \\ & \text { 1-1-farmer } & \text { not-SC1-see-CAU-?-FV } & \text { 2-2-child } & 10-10 \text {-dog }\end{array}$

(77) $\quad[\alpha[\mathrm{NP} a$-ba-ntwana $][b-a[\beta(u$ - $) m$-limi $]]]$

Some speakers ( 2 out 7 consultants) also reject (78), where the possessor NP is augmented, but the possessee is Aug-less:
A-nd-azi
ba-ntwana
b-o-m-limi
not-I-know 2-child SC2-of.1-1-farmer
"I don't know any of the farmer's children."

For these speakers, evacuation of the phrase $\beta$ containing the augmented possessor NP in (79) must pied-pipe the entire $\alpha$-projection:

$$
[\alpha[\mathrm{NP}(a) \text {-ba-ntwana }][b-a[\beta,-m-\text { limi }]]]
$$

That is, these speakers are comparable to the speakers that reject (63.a), i.e. the $\mathrm{V}-+$ pattern in double object constructions:

$$
\begin{aligned}
& \text { a. U-m-limi a-ka-bon-is-ang-a ba-ntwana i-zi-n-ja } \\
& \text { 1-1-farmer not-SC1-see-CAU-?-FV 2-child 10-10-10-dog } \\
& \text { "The farmer didn't show any children the dogs." }
\end{aligned}
$$

\section{Two types of relative clauses}

Visser (2008) points out that the shape of a relative clause in Xhosa reflects whether it modifies an augmented or an Aug-less NP and relates this to a distinction between definite/specific NPs and non-specific NP. In subsection 7.2, I present an implementation of this idea consistent with the analysis developed in the preceding sections. But first, I will argue that the specific syntactic assumptions adopted in section 6.3 play a crucial role by explaining an asymmetry that cannot easily be accounted for in terms of definiteness or specificity.

\subsection{The Relative Concord}

An interesting fact relevant to any account of the augment is that relative clauses come in two different forms according as they modify augmented or Aug-less NPs. A relative clause on an augmented NP has to have a "relative concord" (RC) like the $a$-in (80): ${ }^{48}$

\footnotetext{
${ }^{48}$ The different phonological shapes of the RC can be derived by having the $a$ coalesce with a following Aug agreeing with the SC. Thus, the RC seems structurally similar to demonstratives of position 1 which can be analysed as [ $a$ [ $\left.\operatorname{Aug}_{\mathrm{i}}\left[\mathrm{SC}_{\mathrm{i}}\right]\right]$ preceded by $l$ in the weak classes, i.e. $(l)\left[a\left[\mathrm{xp} \mathrm{Vi}_{\mathrm{isc}} \mathrm{C} / \mathrm{null}\left[\mathrm{xp}_{\mathrm{i}}\right]\right]\right]$ on the account of the relation between the Aug and the SC proposed in section 2.1. The relationship between the RCs and the demonstratives is discussed in Zeller (2006).
} 


$$
\begin{array}{lll}
\text { U-bon-e } & a \text {-ba-fazi } & *(\boldsymbol{a} \text { - }) \text { ba-gul-a-yo } \\
\text { SC1-see-RP } & \text { 2-2-woman } & *(\mathrm{RC} 2-) \text { SC2-sick-FV-REL } \\
\text { "He saw the/some sick women." }
\end{array}
$$

But a relative clause modifying an Aug-less NP can lack the RC:

$$
\begin{array}{lcl}
\text { A-ka-bon-ang- } a & b a-f a z i & (\boldsymbol{a} \text {-) } b a-g u l-a-y o \\
\text { not-SC1-see-?-FV } & \text { 2-woman } & \text { (RC-)SC2-sick-FV-REL } \\
\text { "He didn't see any sick women." } &
\end{array}
$$

I agree with Visser (2008) that the fact that Aug-less NPs are non-specific (in the sense that they come with a free s-variable) plays a role. But the appearance of a $\mathrm{RC}$ cannot be reduced to agreement between the relative clause and the head with respect to a feature [+/- specific ] (seeing the RC and the Aug as exponents of [+ specific]), since the $\mathrm{RC}$ is also possible in a relative clause modifying an Aug-less NP. For the same reason, we cannot exclude (80) without the RC $a$ by saying that augmented NPs and relatives with RCs both correspond to sets of entities of type $\mathrm{x}$, while Aug-less NPs and relatives without an RC correspond to sets of entities of a different type y so that the set of things denoted by an RC-less relative can only intersect with the set of things denoted by an Aug-less NP. Since intersection is symmetric, this would also exclude (81) with an RC in the relative clause. Also, the RC does not appear to relate to the relativized NP, since in general, it shows class-agreement with the following SC rather than with the relativized NP. ${ }^{49}$

On the other hand, the fact that a relative clause modifying an augmented NP must have a RC while the $\mathrm{RC}$ is optional in a relative clause modifying an Aug-less NP, is reminiscent of the fact that an Aug-less NP cannot follow an augmented NP while an Aug-less NP can be followed by either an Aug-less or an augmented NP. Above, the latter fact was analyzed in terms of evacuation movement applying to V-projections containing an augmented NP. Now, I propose that the same analysis be applied to the asymmetry involving RCs, taking the $\mathrm{RC}$ to be similar to an Aug. (On the analysis in footnote 48, the RC actually contains an Aug.)

This requires that the relative clause with a RC can be evacuated from the VP stranding a modified Aug-less NP, just as the V-phrase containing an augmented second object can be evacuated stranding the higher V-phrase containing an Aug-less first object. Alternatively, the relative clause doesn't have an RC and isn't evacuated. When the modified NP is augmented, the $\mathrm{V}$-phrase containing it must be evacuated, and the modifying relative clause is carried along and must therefore have a RC. This is similar to what happens when the first of two objects is augmented: The smallest V-phrase dominating the first object must then be evacuated, and since this V-phrase also contains the second object NP, the second object must be augmented too.

\footnotetext{
${ }^{49}$ My consultants accept only one type of relative clause where the RC agrees with the relativized NP rather than the SC. When the SC is the "dummy" SC15 as in (i), the RC agrees with the relativized NP:

(i) I-n-tle i-n-to e-ku-funek-a ndi-y-enz-e

9-9-nice 9-9-thing RC9-SC15-is.necessary I-OC9-do-SUBJ

"It is nice, the thing that I must do."
} 
From this perspective, a relative clause looks like a nominalized clause subject to caselicensing and with an s-variable with the same properties as a s-variable associated with a regular NP.

\subsection{RC-less relatives compared to Romance subjunctive relatives}

The s-variable associated with an augmented relative clause will be assigned a specific situation $\mathrm{S}_{\mathrm{i}}$ as its value by the RC, while it must be bound by a (negative) existential quantifier when the relative clause is RC-less. Thus, the augmented version of the relative clause in (81) gives rise to the representation in (82.a), while the RC-less version gives rise to (82.b):

$$
\begin{aligned}
& \text { a. not some s', } x \text { some } \mathrm{s}\left(\mathrm{VP}(\mathrm{x}, \mathrm{s}) \text { and } \mathrm{NP}\left(\mathrm{x}, \mathrm{s}^{\prime}\right) \text { and relative clause }\left(\mathrm{x}, \mathrm{s}_{\mathrm{i}}\right) \text { and } \mathrm{s}_{\mathrm{i}}<\mathrm{s}^{\prime}<\mathrm{s}\right) \\
& \mathrm{b} \text { not some } \mathrm{s}^{\prime}, \mathrm{x} \text { some } \mathrm{s}\left(\mathrm{VP}(\mathrm{x}, \mathrm{s}) \text { and } \mathrm{NP}\left(\mathrm{x}, \mathrm{s}^{\prime}\right) \text { and relative clause }\left(\mathrm{x}, \mathrm{s}^{\prime}\right) \text { and } \mathrm{s}^{\prime}<\mathrm{s}\right)
\end{aligned}
$$

(82.b), the representation of (83.b), entails the representation (82.a) of (83.a), since the relative clause in (82.b) denotes individuals falling under the description of the relative clause in any arbitrary situation rather than just in the specific situation $\mathrm{s}_{\mathrm{i}}$ :

$$
\begin{array}{llll}
\text { a. } & \begin{array}{l}
\text {-ka-bon-ang- } a \quad \text { ba-fazi } \\
\text { not-SC1-see-?-FV 2-woman }
\end{array} & \begin{array}{l}
\boldsymbol{a} \text {-ba-gul-a-yo } \\
\text { "HC2-SC2-sick-FV-REL }
\end{array} \\
& \text { "He didn't see any sick women." } & \\
\text { b. } & \begin{array}{l}
\text { A-ka-bon-ang- } a \quad \text { ba-fazi } \\
\text { not-SC1-see-?-FV 2-woman }
\end{array} & \begin{array}{l}
\text { ba-gul-a-yo } \\
\text { (RC-)SC2-sick-FV-REL }
\end{array} \\
& \text { "He didn't see any sick women." } &
\end{array}
$$

This view is similar to Panzeri's (2006) idea that the subjunctive mood in the relative clause in the Italian (84.b) widens the denotation of the relative clause by having the relative clause evaluated with respect to a modal base rather than with respect to the actual world: ${ }^{50}$

$\begin{array}{lllll}\text { a. Non ho visto un uomo che era } & \text { ricco } \\ \text { not I.have seen a man that was.ind } & \text { rich } \\ \text { "I haven't seen a man who was rich." } & & \\ \text { b. Non ho visto un uomo che fosse } & \text { ricco } \\ & \text { not I.have seen a man that was.subj } & \text { rich }\end{array}$

According to Panzeri (2006: 67), “ [T] he subjunctive version in [(84.b)] makes a stronger claim than its indicative counterpart. [(84.a)] may mean that there was a specific rich man I haven't seen - maybe I did see some rich men, but I haven't recognized them as such; [(84.b)] on the other hand claims that of all the men I have seen, I can tell you that none of them was rich." This semantic difference seems to flow rather naturally from assigning the sentences in (84) semantic representations like (85): ${ }^{51}$

\footnotetext{
${ }^{50} \mathrm{~A}$ modal base is a collection of possible worlds including the actual one and perhaps resembling it in certain ways. A possible world can be seen as a maximal set of situations.

${ }^{51}$ The distribution of the two types of relative clauses in Romance is comparable to the distribution of augmented and RC-less relatives in Xhosa. A relative clause modifying an indefinite non-specific noun phrase can be either subjunctive or indicative, while a relative clause modifying any other type of noun phrase (except for noun phrases containing a superlative) must be in the indicative mood.
} 
a. not some $\mathrm{s}^{\prime}, \mathrm{x}$ some $\mathrm{s}\left(\mathrm{VP}(\mathrm{x}, \mathrm{s})\right.$ and $\mathrm{NP}\left(\mathrm{x}, \mathrm{s}^{\prime}\right)$ and relative clause $\left(\mathrm{x}, \mathrm{s}_{\mathrm{i}}\right)$ and $\left.\mathrm{s}_{\mathrm{i}}<\mathrm{s}^{\prime}<\mathrm{s}\right)$

b. not some s', $\quad$ some $\mathrm{s}\left(\mathrm{VP}(\mathrm{x}, \mathrm{s})\right.$ and $\mathrm{NP}\left(\mathrm{x}, \mathrm{s}^{\prime}\right)$ and relative clause $\left(\mathrm{x}, \mathrm{s}^{\prime}\right)$ and $\left.\mathrm{s}^{\prime}<\mathrm{s}\right)$

On this analysis, the specificity of un uomo 'a man' in (84.a) comes from the fact that the indicative relative clause only denotes individuals that are rich in some specific situation $\mathrm{si}_{\mathrm{i}}$ and that the denotation of the relative construction as a whole corresponds to the intersection of the set of individuals denoted by the relative clause and the set of individuals denoted by the NP. That is, even if the NP itself has a s-variable bound by an existential quantifier as in (85.a), the NP cannot be interpreted as non-specific.

By parity of reasoning, we should now expect there to be a meaning difference between the Xhosa sentences in (83) matching Panzeri's characterization on (84.a) vs. (84.b), since the sentences in (83) should also map onto representations like those in (85). That is, ba-fazi in (83.a) should only have a specific reading even though it is Aug-less. I have not been able to find out whether this is correct.

The similarity between RC-less relatives and subjunctive relatives in Romance may suggest that relative clauses are in a mood comparable to the Romance subjunctive, but the addition of a RC removes the "widening effect" that Panzeri talks about, by assigning a specific value to the s-variable of the clause. In fact, the verb in Xhosa relative clauses shares some of the morpho-syntactic characteristics that are standardly associated with subjunctive verbs in Xhosa: The SC1 is $a$ both in relative clauses and with subjunctive verbs as opposed to $u$ with indicative verbs and $e$ with "participial" verbs ${ }^{52}$ and the negation is -nga- appearing right after the SC as with subjunctive and participial verbs rather than the pre-SC $a$-occurring with indicative verbs. But whereas the final vowel of the verb is $-e$ in (positive) subjunctive sentences, it is $-a$ in relatives as in (positive) indicative and participial clauses. For this reason, it is generally claimed that there is a specific mood called "relative mood" in a classification based exclusively on morpho-syntactic criteria.

It is unclear why only a single mood should be available in Xhosa relatives whereas Romance relatives can be either indicative or subjunctive. However, Zeller (2006) cites the following Zulu example from Poulos (1982: 172) illustrating what Poulos calls relativization Strategy 2:53

$$
\text { I-Ngisi eli-baba u-hlal-a e-ndl-ini y-a-lo }
$$

5-Englishman Dem5-1.father SC1-live-FV LOC-9-house-LOC SC9-of-pro5

"the Englishman in whose house my father is living"

This example is remarkable for several reasons. In this context, it seems potentially significant that a demonstrative (but see footnote 53), i.e. eli 'this' agreeing with the modified NP and

\footnotetext{
${ }^{52}$ But it is $u$ in relatives too when the subject is relativized except when the relative clause is negated. The $e$ with participial verbs comes from $a$ coalescing with a following "latent" $i$.

${ }_{53}$ Eli differs from the $\mathrm{RC}$ of class 5, which is $e$, but also differs from the class 5 demonstrative leli in Zulu by lacking the initial $l$. Seen as a demonstrative, it could have been parsed as a postnominal demonstrative modifying $i$-Ngisi so that the translation should be 'this Englishman in whose house my father is living', which would not affect the following discussion in the text. But the fact (not discussed in the text) that the subject NP baba 'my father' is Aug-less suggests that eli is inside the relative clause.
} 
placed in a pre-subject position, appears instead of a regular RC in the post-subject position agreeing with the subject as in the alternative construction in (87):

$$
\begin{aligned}
& \text { I-Ngisi u-baba } \quad \begin{array}{c}
\text { a-hlal-a } \\
\text { 5-Englishman 1-father }
\end{array} \text { SC1-live-FV LOC-9-hi y-a-lo } \\
& \text { "the Englishman in whose house my father is living" }
\end{aligned}
$$

It is also striking that the $\mathrm{SC} 1$ in (86) is $u$ rather than $a$ as in (87), although it is not the subject that has been relativized. This second fact suggests that the relative clause is in the indicative mood in (86).$^{54}$ The fact that the regular $\mathrm{RC}$ is absent in (86) might then be due to there being no need to use an $\mathrm{RC}$ to provide a value for the s-variable associated with an indicative relative clause. That is, the indicative provides an element that assigns a value to the s-variable of the clause as assumed above for Romance. In this connection, it is also striking that the only one of my Xhosa consultants who accepts (86), did not allow the demonstrative to be left out even when the modified NP was Aug-less while allowing the RC to drop in examples like (87). This is consistent with the assumption that the demonstrative in (86) does not fulfil the functions of a RC.

\title{
8. Conclusion
}

I think the similarities between the French de NPs and Aug-less NPs in Xhosa highlighted in section 3 as well as the similarities between French indefinite des NPs and indefinite augmented NPs provide good reasons to think that the augment is really akin to the French definite article while Aug-less NPs are just bare NPs. This conclusion is independent of the specific analytical proposals offered in the subsequent sections.

According to these proposals, the semantic properties of Aug-less NPs, in particular the fact they need to be in the scope of negation (in the Xhosa spoken by my consultants) and block certain readings of augmented NPs, are taken to follow from the fact that they are bare NPs. The idea that this is related to bare NPs coming with a free s-variable, is essentially an implementation of Visser's (2008) proposal that Aug-less NPs are non-specific.

All of this is largely independent of the specific details of the syntactic analyses in section 6, which, however, come close to capturing the distribution of Aug-less NPs over syntactic positions in the variety of Xhosa my data comes from.

\begin{abstract}
Abbreviations
$\mathrm{SCX}$ - the subject concord of class X; OCX - the object concord of class X; RCX - the relative concord of class X; proX - a pronoun in class X; DemX - a demonstrative in class X; APPL the applicative verbal extension; CAU - the causative verbal extension; RP - the recent past tense suffix; FV - the final vowel of indicative present tense verbs in sentences without negation; NFV - the final vowel under negation; SUBJ - the subjunctive final vowel; REL - a suffix that may appear on VP-final verbs in relative clauses; Q - an interrogative particle.
\end{abstract}

\footnotetext{
${ }^{54}$ I don't know whether negation would be expressed by pre-SC $a$ - or post-SC -nga- in (86).
} 
Augmented nouns are glossed as $\mathrm{X}-\mathrm{X}$ - noun where $\mathrm{X}$ is the number of the N's class. $\mathrm{X}-\mathrm{N}$ glosses an Aug-less noun.

\section{References}

Buell, L. 2009. The Distribution of the Nguni Augment. Unpublished hand-out from the Bantu Augment Workshop, Leiden University.

Carstens, V. and L. Mletshe. 2016. N-words in disguise: a negative concord approach to augmentless NPIs in Xhosa and Zulu. Natural Language and Linguistic Theory 34(3): 761804. https://doi.org/10.1007/s11049-015-9320-x

Collins, C. and P. Postal. 2014. Classical NEG Raising. Cambridge: MIT Press.

Dayal, V. 1998. Any as inherently modal. Linguistics and Philosophy 21: 433-476.

de Blois, K.F. 1970. The Augment in the Bantu Languages. Tervuren: Musée Royal de l'Afrique Centrale.

Diesing, M. 1992. Indefinites. Cambridge: MIT Press.

Doetjes, J. 1994. Quantification at a distance and event relatedness. Linguistics in the Netherlands 1994: 13-24.

Doke, C.M. 1927. Text-book of Zulu Grammar. Cape Town: Longmans, Green.

Halpert, C. 2016. Argument Licensing and Agreement. Oxford: Oxford University Press.

Hamblin, C.L. 1973. Questions in Montague English. Foundations of Language 10: 41-53.

Kadmon, N. and F. Landman. 1993. Any. Linguistics and Philosophy 16(4): 353-422. https://doi.org/10.1007/bf00985272

Kayne, R.S. 1981. ECP Extensions. Linguistic Inquiry 12(1): 93-133.

Kayne, R.S. 1983. Connectedness. Linguistic Inquiry 14(2): 223-249.

Kayne, R.S. 2002. On some prepositions that look DP-internal: English of and French de. Catalan Journal of Linguistics 1: 71-155. https://doi.org/10.5565/rev/catj1.56

Kratzer, A. 2014. Situations in natural language semantics. In E.N. Zalta (ed.) Stanford Encyclopedia of Philosophy (Summer 2019 Edition). Available online: https://plato.stanford.edu/archives/sum2019/entries/situations-semantics

Mzolo, D. 1968. The Zulu noun without the initial vowel. African Studies 32: 163-181. https://doi.org/10.1080/00020186808707297 
Nilsen, Ø. 2003. Eliminating Positions: Syntax and Semantics of Sentence Modification. Utrecht: LOT.

Obenauer, H-G. 1983. Une quantification non canonique: la "quantification à distance". Langue française 58: 66-88. https://doi.org/10.3406/lfr.1983.6415

Obenauer, H-G. 1984. On the identification of empty categories. The Linguistic Review 4: 153202.

Panzeri, F. 2006. Subjunctive relative clauses. In P. Denis et al. (eds.) Proceedings of the 2004 Texas Linguistics Society Conference. Somerville: Cascadilla Proceedings Project. pp. 60-68.

Poulos, G. 1982. Issues in Zulu Relativization. Department of African Languages: Rhodes University.

Ramchand, G. 2018. Situations and Syntactic Structures. Cambridge: MIT Press.

Taraldsen, T. 2010. The nanosyntax of Nguni noun class prefixes and concords. Lingua 120: 1522-1548. https://doi.org/10.1016/j.lingua.2009.10.004

Taraldsen, T., L. Taraldsen Medova, and D. Langa. 2018. Class prefixes as specifiers in Southern Bantu. Natural Language and Linguistic Theory 36(4): 1339-1394. https://doi.org/10.1007/s11049-017-9394-8

Visser, M. 2008. Definiteness and specificity in the isiXhosa determiner phrase. South African Journal of African Languages 1: 11-29. https://doi.org/10.1080/02572117.2008.10587298

von Staden, P.M.S. 1973. The initial vowel of the noun in Zulu. African Studies 32: 163-181. https://doi.org/10.1080/00020187308707406

Zeller, J. 2006. On the relation between noun prefixes and grammaticalisation in Nguni relative clauses. Studia Linguistica 60(2): 220-249. https://doi.org/10.1111/j.1467-9582.2006.00138.x 